\title{
5. The Solar Nation of Tokelau An adventure in documentary making
}

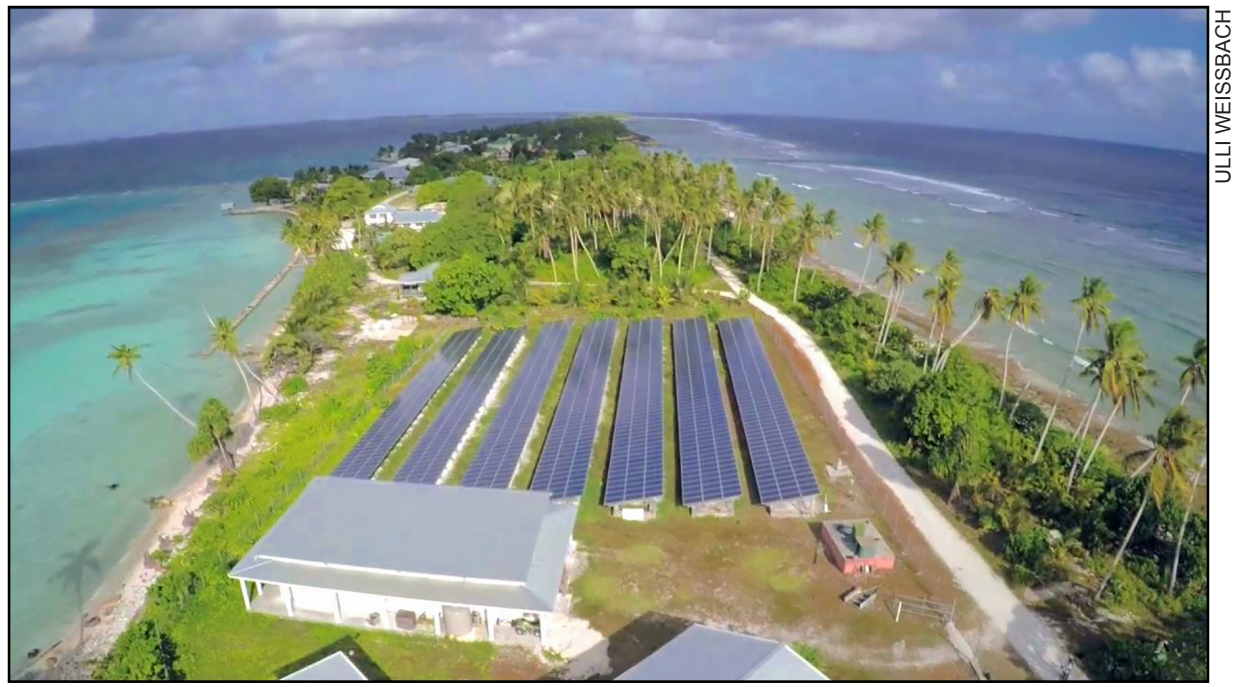

Figure 1: Powering a people — The Solar Nation of Tokelau.

Commentary: The Tokelau solar project first came to the attention of this filmmaker at a Pacific Energy Summit in Auckland, New Zealand, in 2013. Three remote islands in the Pacific becoming the first 100 percent solarpowered nation on earth and setting an example for the complete adaptation of sustainable energy sounded like a story too good to be overlooked by mainstream news media. However, research demonstrated that this was indeed widely ignored. So the author set about his usual practice of pitching the idea to his colleagues at German Television. The fact that he had already made a short documentary about Tokelau in 2006 (ARTE TV Reportage: Independence Referendum in Tokelau) and was thus familiar with the territory and its people, worked in his favour. But funding proved to be a difficult challenge because the logistics of the project demanded a longer than usual shooting schedule and crew time. In the end, a solution was found by accessing additional funding and negotiating a bulk deal with the crew to make The Solar Nation of Tokelau (2014).

Keywords: climate change, development, documentaries, energy, environmental journalism, filmmaking, Pacific, solar energy, sustainability, Tokelau

\section{ULRICH WEISSBACH}

Filmmaker, Pacifica Productions Ltd, Auckland 


\section{Introduction}

7 HE Solar Nation of Tokelau is a 44 minute television documentary produced and directed by me. It was commissioned in 2014 by SWR, a broadcaster of the ARD network in Germany (German TV One) and broadcast by ARTE TV, an arts and culture channel broadcasting to over 200 million viewers in central Europe. The original German version was entitled Die Sonnenmenschen von Tokelau (The Sunny People of Tokelau) and the French version Le Paradis Solaire de Tokelau (The Sunny Paradise of Tokelau), as ARTE is a French-German joint venture and broadcast bilingual programmes ${ }^{1}$. Later, an English version was produced for international distribution, entitled The Solar Nation of Tokelau.

The first broadcast over ARTE's European network was on 21 September 2015 with multiple replays following in France and Germany. The New Zealand premiere took place on 8 August 2016 in the historic Devonport Victoria Cinema, Auckland. Since then it was selected by the Festival International du Film documentaire Océanien (FIFO) 2017, an Oceania documentary film festival in Tahiti (www.fifo-tahiti.com), and GreenMe (www.greenme.de), an environmental film festival in Berlin.

Apart from me (director/producer), most of the film crew $^{2}$ consisted of New Zealand professionals. Only the main video editor was originally from Germany, like me. This article outlines the complex logistics and other challenges facing a European (Palagi) filmmaker in the Pacific Islands, as experienced with this Tokelau documentary.

\section{The story and its sale}

The author first heard about the Tokelau solar project at a Pacific Energy Summit $^{3}$ in Auckland in 2013. Three remote islands in the Pacific becoming the first 100 percent solar-powered nation on earth and setting an example for the complete adaptation of sustainable energy sounded like a story too good to be overlooked by mainstream news media. However, research demonstrated that this was indeed widely ignored.

So the author set about his usual practice of pitching the idea to his colleagues at German Television. The fact that he had already made a short documentary about Tokelau in 2006 (ARTE TV Reportage: Independence Referendum in Tokelau) and was thus familiar with the territory and its people worked in his favour. But funding proved to be a difficult challenge because the logistics of the project demanded a longer than usual shooting schedule and crew time. In the end, a solution was found by accessing additional funding and negotiating a bulk deal with the crew to make The Solar Nation of Tokelau. 


\section{Solar energy and the example of Tokelau}

The maths and physics behind solar energy deliver some mind-boggling figures. Physically the sun is nothing but an open nuclear fusion reactor, contained by its own gravity. Fusion transforms matter into pure energy, a process that happens in every star of the universe. This way, our sun emits almost unlimited amounts of energy. Only the small part that is absorbed by the earth's atmosphere is estimated at 174 Petawatt (PW) $174,000,000,000,000,000$ Watt. And that again represents more energy per hour than the earth's current energy demand in one year (Solarkonstante, n.d.).

Calculations speak for solar power as the ideal power source. It can be captured

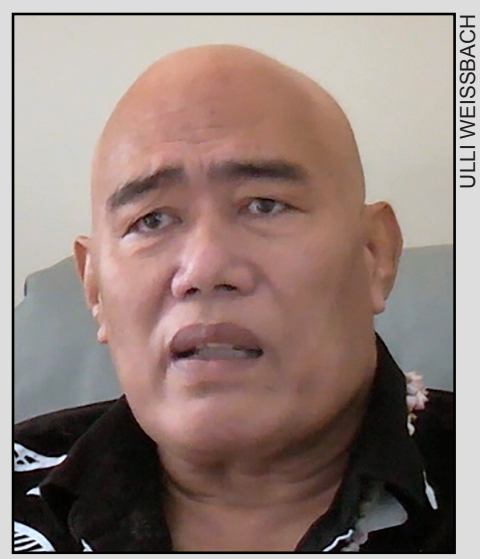

Figure 2: Solar mastermind Foua Toloa, the late Ulu o' Tokelau. passively with solar panels or other collectors. It indirectly creates wind and ocean currents that can drive turbines. It also drives the natural process of photosynthesis that feeds the world.

The sun certainly shines generously on Tokelau, three little islands close to the equator, where sun exposure is at a maximum. This inspired an idea in a Tokelau politician's head: Foua Toloa, Faipule (mayor) of the island of Fakaofo and Ulu o' Tokelau (Head of Government) for two years. Speaking at the United Nations Climate Conference in Durban (2011), he pledged: 'We have no intention of leaving (our islands). This is a God-given land; we have a culture, a language, an identity and a heritage. We want to preserve Tokelau for future generations (Interview with Foua Toloa, 2015).

Foua announced that Tokelau would, in 2012, 'switch entirely to renewable energy', as the territory would 'switch off its old diesel generators and be powered by a NZ $\$ 7.5$ million solar PV system designed to provide 90 percent of its energy. The rest will come from home-made coconut oil'. He urged the rest of the world to move towards renewable energy in a similar manner (Foua Toloa, n.d.).

It was the birth of Tokelau's ambitious 'Renewable Energy Project', which would see Tokelau become the first nation on earth to be almost 100 percent powered by solar energy and reduce its carbon footprint to almost zero.

The machinery behind the project is three solar power plants-one on each island - with a combined output of 1 Megawatt. According to the NZ subcontractor, solar installation company PowerSmart, the project 'involved the installation of 4,032 photovoltaic panels, 392 inverters and 1,344 batteries across the three atolls-Fakaofo, Nukunonu, and Atafu (PowerSmart, 2012).

The use of batteries as backup power for nights and other no-sunshine periods makes the Tokelau solar installation the largest off-grid power plant in the world; with 'off-grid' meaning not connected to any existing power grid. In most other locations on earth, solar power installations deliver their excess power 
into the existing power grid, thereby bypassing the need for storage. But having never been connected to an outside power grid, Tokelau's off-grid solar solution makes it truly independent in its power supply. Something no nation can claim.

Before Tokelau's solar transition, its diesel generators were burning around 200 litres of fuel daily on each atoll. Tokelau's total consumption amounted to more than 2,000 barrels of diesel each year, costing more than NZ\$1 million. The cost and physical labour to ship them from Samoa to Tokelau and manhandle them from the ferry into boats and ashore is on top of this.

Although Tokelau's solar power is now generated for free, the local government decided still to charge the pre-solar electricity price of 50 cents per kWh. The accumulated capital will be used to pay for maintaining the system and future upgrades.

What about the other side of the energy equation-the greenhouse gas emissions of the former diesel generators. David Sheppard of Islands Business magazine did some interesting calculations:

Prior to the advent of the Tokelau Renewable Energy Project (TREP), the inhabitants of these three atolls used fossil fuel (diesel) power generators for their electricity needs. A typical Tokelauan home consumes between 5 and 14 kilowatt-hour (kWh) per day, accounting for an average demand for the country of 150 kilowatts per day. Based on this approximation, Tokelau emitted 1,695 kilogrammes of carbon dioxide per day when using diesel fuel for electricity generation. This translates to 620.5 metric tonnes of greenhouse gases emitted by Tokelau in one year for power generation" (before solar). (Sheppard, 2013)

A saving of 620.5 metric tonnes of greenhouse gases per year may look minuscule compared to large, industrialised nations. But it is all Tokelau could do. And it has done it.-Ulli Weissbach

\section{Logistics-a nightmare}

Given the remoteness of the three Tokelau islands, transport of crew and equipment was the biggest challenge from the beginning (pre-production planning). The three atolls, with a total population of only 1,500 (Tokelau Census, 2016) on only $10 \mathrm{~km}^{2}$ of land, are situated in the middle of the Pacific, $500 \mathrm{~km}$ north of Samoa, far away from shipping lines, without an airport or a harbour.

The only connection is an unreliable ferry service between Samoa and Tokelau that operates every two weeks. The ferry carries people and supplies to all three islands on a three to four-day round trip, stopping at each island for only a few hours of loading and unloading. Which means that if a minimum film crew of three - director, cameraman, sound operator - want to spend a reasonable amount of days on each island, they would have to stay at least two weeks on each island to wait for the next ferry to take them to the neighbouring island. But six weeks shooting time would have definitely blown the budget.

The three atolls Atafu, Nukunonu and Fakaofo are only 90 kilometers 
(between Atafu and Nukunonu) and 68 kilometres (Nukunonu-Fakaofo) apart, but the fishing boats on each island are not safe enough to bridge this divide. So other transport options were explored, like chartering a boat or even a helicopter from Samoa to Tokelau. But charter boats were still outside the budget limits and there was no helicopter in Samoa that had a long enough range to fly to Tokelau and back (Smith, 2017).

Also, no time and budget had yet been set aside, to do a proper 'recce', a research trip to Tokelau to get consent from the locals and organise a shooting schedule. Solutions for both, crew transport and recce, fell in place with time. The recce could be done by joining an annual maintenance trip of the solar engineering team, for which a separate ferry was chartered to visit all three islands in 2014. And an earlier collaboration with the German ocean foundation OKEANOS (okeanos-foundation.org/sustainable-sea-transport/) proved to be valuable in providing a reasonable and safe transport option. OKEANOS supports sustainable sea transport in the Pacific by building replicas of traditional Polynesian vaka and using them as 'school ships' for young Polynesian navigators, who want to learn the ancient art of Polynesian navigation. OKEANOS' vaka are seaworthy for long distance travel in the Pacific, equipped with solar panels, electric motors and modern navigation tools. But their design follows the classic Polynesian two-hulled sailing vaka, with which the Polynesians conquered the Pacific thousands of years ago.

Thanks to OKEANOS, the film crew was able to use one of its vaka (Rangi) and crew for their shooting trip to Tokelau in May/June 2015. For this project, the vaka was relocated from Tahiti to Samoa-a distance of more than 4,000 $\mathrm{km}$ - in a record time of 12 days. The trip with film crew from Samoa to Tokelau took only 60 hours, 24 hours longer than the ferry. In terms of dramaturgy it was only natural to incorporate the vaka trip into the story.

\section{Island authorities and politics}

At first it seemed political and administrative responsibilities were clear. Tokelau was a New Zealand territory, administered by the government in Wellington, i.e. the Ministry of Foreign Affairs and Trade (MFAT). But as more research and production planning progressed, it became clear that MFAT had almost no control over the internal affairs of Tokelau. Or, as MFAT defines its relationship to Tokelau more diplomatically:

Tokelau is a New Zealand territory, yet has its own political institutions, judicial system, public services, telecommunications and shipping systems, and full control of its budget. New Zealand provides about 60 percent of Tokelau's annual government budget, and we're responsible for their defence and security, including maritime surveillance and other defence 
programmes. We've never had a physical presence in Tokelau-our administration is light-handed with little influence on Tokelau's distinct culture or everyday life on the atolls. (MFAT, n.d.)

There is an MFAT 'Administrator' in charge for Tokelau, who would have been a 'Governor' in colonial times. But the notion that Tokelau is a 'colony' of NZ has to be avoided of course. His role is described on The Government of Tokelau's website as:

Administrative and legislative powers of the Administrator of Tokelau are formally delegated to the three Taupulega (Village Council of Elders) of Tokelau as the highest authority. Authority for national issues is redelegated to the General Fono to deal with issues beyond those properly undertaken by each village alone. Consistent with this power structure is a devolution of most public service delivery to the villages. In each village a General Manager along with other staff members, including teachers and medical staff, support each Taupulega in their government functions. National-level administration is primarily done by the national public service, most of which is based in Apia. (Government of Tokelau, n.d.)

Although formally a dependent territory of New Zealand, Tokelau can basically rule itself and decide how its NZ-sponsored budget is spent. After declining the offer of independence in a referendum held in 2006 (Tokelauan self-determination, 2006), Tokelau enjoys the best of both worlds: NZ financial support and virtual independence as a self-ruling entity.

In practical terms, most of the administration is outsourced to the 'Office of the Council for the Ongoing Government of Tokelau', located in Samoa's capital Apia, also called the 'Tokelau Apia Liaison Office'. This office executes the decisions of the island councils and the national Fono.

It took me some time to realise that I could not expect any support from MFAT in arranging my shooting trip. Nor was the 'Tokelau Apia Liaison Office' in a position to make any decision without the consent of the Taupulega, the village council of elders with a membership of 10 to 12 seniors representing a village (island) maximum of 500 people.

Combined with a high degree of rivalry between the three islands and complex internal politics and intrigues on each island, this power structure proved to be almost insurmountable when it came to planning and executing the film production. Even though the author had done a preparatory trip to Tokelau one year before the actual shooting and thought he had the elders on his side, the mood and composition of the councils had changed again when the film crew arrived. In one case the obstruction had reached a high point, when the vaka and film crew were only allowed to land on the atoll after intervention from the 
'Ulu', the titular head of Tokelau. He was to be interviewed for the documentary and happened to live on this island.

There were numerous other hurdles and obstacles to overcome. But in the end everything fell in place in a way that can only be described as the 'Pacific Way'. The film crew enjoyed the full cooperation of each island and the author again learnt a lesson: that no amount of planning can prevent a completely different course of events, when dealing with Pacific islanders. Or, in other words: Don't worry, it will happen, but in a totally different way.

\section{Island time}

'Island time' is another term often used in the islands to calm down Europeans waiting nervously for something to happen. It means that islanders have a different concept of time, which allows them to operate in another continuum than that of the outsider or visitor. This is hard to prove by any scientific means, be it cosmology or psychology. But it is a widely accepted concept and should be acknowledged by anyone working in the islands.

\section{Unexpected events}

The general rule in the Pacific is: Expect the unexpected. Sometimes things happen faster than anticipated, like the launching of a canoe or the catching of a fish. And sometimes things happen, that nobody has ever dreamt of. For a documentary filmmaker they present invaluable opportunities to give their story another twist or just a comical moment, like the twinkle of an eye or hearty laughter.

In order to catch these little moments, the camera operator needs a sense of anticipation and fast reaction time. Nothing that can be learned in any way; it only comes with years of experience. A good briefing by the director/producer (me in this case), who needs to communicate his or her story and its intended style to the whole crew.

\section{Visualisation}

Having a European audience in mind, I knew from the beginning how important it was to visualise the geographic anomaly of an atoll. In nature an atoll is the crater rim of an underwater volcano that forms an irregular ring of small, flat islands, so-called motu around a lagoon (the crater). No one has better described the nature of an atoll than James Mitchener, the American writer who travelled the Pacific extensively during World War Two:

This is the wonder of an atoll, that you are safe within the lagoon while outside the tempest rages. The atoll becomes a symbol of all men seeking refuge, the security of home, the warmth of love. Lost in a wilderness of 
ocean, the atoll is a haven that captivates the mind and rests the human spirit. (Michener, 1951)

Two techniques lent themselves to visualise the nature of an atoll:

1. Google Earth Animation allows an experienced video editor to zoom into any location from a global perspective and create virtual 3D flights over objects and even under water. It was used to show the location of Tokelau's three atolls and their geographical nature.

2. A camera drone was used to film real HD aerials of every atoll to demonstrate their limited land area, small settlements and facilities on land. Both techniques proved to be very effective in portraying the unique beauty of an atoll, which probably has never been shown before in this detail and intensity. Surely the Tokelauans themselves, who were later presented with the footage, have never seen their homeland in that way.

\section{Music}

Music is essential for the emotional tone of a documentary. Music supports the pictures and creates a mood for the story, be it happy feelings, or sadness or fear. It is essentially another layer of story telling. For a documentary to be authentic, it is better to use the music of the locality being featured. In the case of Tokelau, the choice was clear: Te Vaka (www.tevaka.com), a Polynesian pop band whose leader and songwriter Ope Foa'i originates from Tokelau.

In more than 20 years of documentary production in the South Pacific, the author was lucky to establish a close relationship with Te Vaka and Ope and has used their music many times. Te Vaka has created a fusion of rock, pop and traditional Polynesian music and is internationally renowned as the number one 'world music' ambassador for the Pacific. With its combination of log drums, guitars and Polynesian voices and lyrics, Te Vaka produces a distinctive 'Pacific sound' or feeling.

More recently, Ope Foa'i was chosen by the Disney Movie company to write the music for its animated feature Moana, a tale about Polynesian migration in the Pacific.

\section{Other elements of the story}

Already in the research and planning stage, it became clear that Tokelau's solar project could only be the core of a much wider narrative about life on an atoll. The sheer remoteness and isolation of Tokelau offered the opportunity to present a unique culture and community as it has existed over many hundreds and thousands of years in the Pacific. 'The Romance of the South Seas' has been portrayed by Herman Melville and numerous other 'South Sea' writers and left a lasting impression on Europeans and their dream of an innocent and peaceful life in the legendary Pacific islands. 
Two important aspects of Tokelau culture perfectly illustrated this romantic dream:

The Inati system of sharing and caring, a sort of primeval communism, where all work and income is shared by the community. For instance, the fishermen - every adult male Tokelauan is a fisherman - share the work of fishing and their catch with the community. Although there are many more aspects to the Inati system, it presents an intriguing example of a 'sharing economy', as it is discussed in economic circles nowadays.

As the practice of fishing has dominated Tokelauan culture and economy since time immemorial, it was worth looking at as well. The sheer abundance of fish, the artistry of the fishermen, the sharing of the catch and its preparation are essential elements of Tokelauan culture. And the depletion of their fishing grounds by foreign fishing pirates presents, after climate change, the other major threat to Tokelau's survival.

\section{Conclusion}

There are many more things that drive a documentary. But the most important contribution always comes from its people, or in film terms 'protagonists'. Despite its isolation and tiny population, Tokelau presented itself as a welleducated, warm-hearted, fun-loving and close-knit community, which catches and serves the best seafood on the planet.

On behalf of the film crew, I wish to thank all Tokelauans for their hospitality and friendly cooperation in this project. They deserve more recognition for what they have achieved with their solar project, more than this documentary can do. They also deserve to survive the consequences of climate change, which threatens their islands.

\section{Notes}

1. 'As the European Culture Channel, ARTE provides cultural programming that fosters understanding among Europeans and brings people together. Since its creation in 1991, ARTE stands for cultural diversity and multilingualism. ARTE uncovers new talent, encourages artistic creativity, and preserves and promotes Europe's cultural heritage. ARTE supports talented film-makers as a co-producer and shows ambitious new creations, daring drama and series. On offer are also bold documentaries, no infotainment but daily news of vital interest to Europeans.' Retrieved from 'ARTE in five languages' from www.arte.tv/sites/en/corporate/des-programmes-pour-tous2/?lang=en\#about

2. Director/producer: Ulli Weissbach, NZ producer: Lisa Walker, DOP: Mark Chamberlin, Sound and drone operator: Sander Dercks, Post-production: Michael Moennich, Editor and Google Animator: Andy Milne.

3. Pacific Energy Summit: Bridging the commercial, public and nonprofit sectors (2013). An annual invitation-only summit. Retrieved from http://pacificenergysummit.org/ 


\section{References}

Foua Toloa (n.d.). Foua Toloa-Wikipedia. Retrieved from https:/en.wikipedia.org/ wiki/Foua Toloa

Government of Tokelau: Administration. (n.d.). Malo ni and welcome to our official website. Retrieved from http://www.tokelau.org.nz/About+Us/Administration.html

Interview with Foua Toloa (2015, June 23). [Video interview by U. P. Weissbach.] Available at https://vimeo.com/210392652

Michener, J. A. (1951). Return to paradise. New York: Penguin Random House.

PowerSmart. (2012, October 29). PowerSmart finishes Tokelau renewable energy project: Power to the people_-PowerSmart finishes world first project to make Tokelau $100 \%$ solar powered. Retrieved from http://powersmartsolar.co.nz/blog/id/413

Sheppard, D. (2013, February 3). Tokelau leads the world on renewable energy. Islands Business. Retrieved from https://www.islandsbusiness.com/2013/item/620-tokelauleads-the-world-on-renewable-energy

Solarkonstante (n.d.). Solarkonstante-Wikipedia. Retrieved from https://de.wikipedia. org/wiki/Solarkonstante

Smith, M. (2017, May 11). Tokelau suspends two officials following helicopter row review. Asia Pacific Report. Retrieved from http://asiapacificreport.nz/2017/05/11/ tokelau-suspends-two-officials-following-helicopter-row-review/

Tokelau: Our Relationship with Tokelau. (n.d.). New Zealand Ministry of Foreign Affairs and Trade (MFAT) website. Retrieved from https://mfat.govt.nz/en/countries-andregions/pacific/tokelau/

Tokelau Census of Population and Dwellings. (2016). Statistics New Zealand. Retrieved from http://www.stats.govt.nz/browse for_stats/people_and_communities/ pacific_peoples/2016-tokelau-census-landing.aspx

Tokelauan self-determination referendum, 2006. (n.d.). Wikpedia. Retrieved from https:// en.wikipedia.org/wiki/Tokelauan_self-determination_referendum, 2006

Weissbach, U. P. (2014). The solar nation of Tokelau. Available at https://vimeo. com/146467851

Ulrich Weissbach is a New Zealand-based German documentary film producer who specialises in documentaries about the Pacific region and its cultures for public broadcasters in Europe. He also tells stories about science and history. He is director of PACIFICA Productions Ltd., Auckland, New Zealand.

ulli@pacifica.info 